\title{
UMA CARTOGRAFIA DE MOLECULARIDADES ATIVAS EDUCACIONAIS A PARTIR DE LINHAS DE FUGAS ARTÍSTICAS
}

\section{A CARTOGRAPHY OF ACTIVE EDUCATIONAL MOLECULARITIES FROM ARTISTIC ESCAPING LINES}

\author{
Filipe Lima Silva \\ Universidade Federal Rural de Pernambuco \\ (Departamento de Educação), Doutorando \\ em Educação em Ciências - Universidade \\ Federal do Rio Grande do Sul (UFRGS), \\ orcid.org/0000-0001-5909-2286 \\ E-mail: filipemp2@hotmail.com

\section{Claudia Glavam Duarte} \\ Programas de Pós-Graduação em Educação \\ em Ciências e Ensino da Matemática (UFRGS) \\ orcid.org/0000-0002-8608-5855 \\ E-mail: claudiaglavam@hotmail.com
}

\section{INTRODUÇÃOO}

A cartografia que propomos neste trabalho parte de linhas de fuga da arte e Lenveredam pelo mapear de uma das obras de autoria do jornalista/artista pernambucano Francisco Ludermir. Nossa intenção com o mapeamento surge da possibilidade de que elementos artísticos em agenciamento constituam estratégias de re(x)istência no acontecimento educação.

Usaremos o termo "obra" para referirmo-nos a uma série de materiais produzidos por Ludemir em seu encontro com mulheres trans e travestis que vivem nas fendas da cidade de Recife. Assim, o material empírico analisado envolve uma caixa de ferramentas que atua junto a potências disruptivas: ensaios fotográficos, áudios, curtas-metragens, entrevistas, artigos jornalísticos, projeções cinematográficas, movimento, intervenções artísticas ("Mulheres: Nascer é Comprido") e o livro "A História Incompleta de Brenda e de Outras 
Mulheres..."1 . Esses elementos nos apontaram linhas de fuga que promovem destruições revolucionárias das estruturas e representações, tanto artísticas quanto educacionais. Especificamente, o trabalho de Ludermir foi protagonizado por 11 mulheres trans e travestis recifenses de diferentes perfis. No entanto, apesar das singularidades, traços em comum emergiram fruto das marcas e cicatrizes presentes em seus corpos. Cada marca é resultante de vivências atravessadas pelo preconceito, violência, exclusão social e pela experiência de transformação do próprio do corpo.

Percorrer os caminhos que chegaram a este trabalho e a necessidade de costurar um mapa dos fluxos contínuos na arte de Chico Ludemir nos permitiram construir um olhar que acreditamos ser relevante para a pesquisa educacional. Dito de outro modo, a possibilidade de trilhar com/sobre/sob o "material empírico", ou vital, deste trabalho nos fez percorrer por lugares onde educações transitam. Essas estavam nas vozes, nas linguagens do corpo, nos métodos utilizados por Ludermir, nas linhas, textos, vídeos e intervenções artísticas. Mas, sobretudo, estava nos afectos e perceptos, nas leituras que fizemos do trabalho desenvolvido pelo autor, bem como das vivências de mulheres travestis e transexuais que nos foram apresentadas.

O encanto pela obra se mostrou na forma de narrativizar o processo de rompimento e eclosão de subjetividades transexuais em movimentos de afrontamento direto aos processos de assujeitamento familiar e escolar e, em efeito, da construção de suas mulheridades. Todos os recortes biográficos partem de contações de si mesmas que se alicerçam na desconstrução e reconstrução das memórias e trazem a possibilidade de transformação de subjetividades através do processo de posar, relatar, performar, recontar, reler-se, rever-se e fabular-se. Os movimentos elencados confrontam o cis-tema,

\footnotetext{
${ }^{1}$ A obra é oriunda de um convite feito ao jornalista e fotografo Chico Ludemir, financiada pelo Ministério da Cultura (PESSOA, 2016; LUDERMIR, 2016; BEZERRA, 2015) junto ao Núcleo Integral de Saúde Coletiva da Universidade de Pernambuco (UPE, 2018) que tinha como proposta inicial um "projeto jornalístico-literário com mulheres que foram designadas homens ao nascer. Seria um desdobramento subjetivo de uma pesquisa epidemiológica que o núcleo estava finalizando, com 11 mulheres trans e travestis de Pernambuco (LUDERMIR, 2016, p. 18). No entanto, o processo criativo foi mais amplo e espontâneo do que o inicialmente proposto, pois reuniu cinema, literatura, fotografia e movimento que tinham como tema central o cotidiano de mulheres transexuais. Apesar do caráter rotineiro, há um choque se comparado a outras vivências, um descostume quanto a essas subjetividades e seus modos de viver, razão pela qual a obra carreia sensações que criam uma nova espacialidade fronteiriça nas fendas da cidade tanto quanto apresentam a possibilidade de nos deslocarmos no tempo.
} 
tentáculo do inconsciente colonial capitalístico (ROLNIK, 2016), que atua no assujeitamento de vivências Queer e produzem mazelas sociais que podem ser vistas em existências imersas em preconceito, exclusão social, violência e morte.

São mulheres e adolescentes assassinadas; crianças que sofrem torturas físicas e psicológicas, alvejadas diuturnamente por não se "enquadrarem" ao cis-tema heteronormativo. Essas transitam nas fendas da cidade, lugares marginais, periferias, ruas escuras do centro comercial da Grande Recife, vivendo, muitas vezes, da prostituição de seus corpos. No entanto, muitas estão ali enfrentando o cis-tema para trazer à tona sua mulheridade e viver com coerência sua existência. Assim, as experiências de transformação do próprio corpo de mulheres transexuais e travestis, muitas vezes feitas de forma clandestina e marginal, rompem um estado de coisas que sustentam os parâmetros de normalidade e normatividade.

Da mesma forma ocorre com a arte hegemônica e pretensiosamente monolítica, ao se confrontar com uma expressão que partilha o sensível e promove ondas de força. Essas trazem potências e devires aos movimentos artísticos, culturais e educacionais, pois tratam-se de contra-fluxos, de re(x)istências.

Nessa perspectiva, a problemática surge da possibilidade de que elementos artísticos, em agenciamento, constituam estratégias de re(x)istência no acontecimento educação. Essa premissa gerou, como pista inicial, a necessidade de costurar um mapa dos fluxos contínuos na arte de Chico Ludemir que nos levasse ao acontecimento. Surgiram movimentos que nos permitiram investigar a pista proposta e desenvolver nossa cartografia viva, com ênfase na molecularidade de linhas de fugas educacionais a partir das subjetividades do autor, da obra e das personagens por ele descritas.

Percebemos que todos os elementos de análise se traduzem em vida, desde o estilo cartográfico de Francisco Ludermir, permeado por heterocronias e heterotopias, até o nosso trans-corpus vibrátil que, mesmo resignado às exigências do jargão acadêmico, se entrega aos afectos e perceptos de uma subjetividade que oxigena o trabalho do artista. Especificamente, analisamos três movimentos de estilo provocados pelo autor: movimento coletivo-político, movimento-estético e movimento-ético. O trans-corpus é articulado em conceitos ante as imagens dos ensaios fotográficos, a poesia política do 
texto e as fotos do livro, a imagem-cristal vivenciada nos curtas-metragens, e a intervenção artística que reuniu quase todo material de pesquisa produzido pelo autor.

Ao mapearmos esses movimentos, encontramos agenciamentos nos quais as educações transitam, sobretudo o ato de aprender entendido como um agenciamento complexo, que concerne às condições de possibilidade do próprio pensamento, que "vai além do saber, esposando a vida toda, inteira, em seu curso apaixonado e imprevisível (SCHÉRER, 2005, p. 1183).

\section{LINHAS DE FUGA DA ARTE PARA PENSARMOS A EDUCAÇÃO}

A atuação cerceadora do cis-tema, enquanto tentáculo do inconsciente colonial capitalístico, identificado por Rolnik (2016), represa os fluxos de criatividade nas mais diferentes esferas de nossa vida tornando-a um elemento fixo mediante elementos comuns de uma identidade globalizada (cosmopolita), ao mesmo tempo em que estão vinculadas aos ritmos frenéticos ditados pelo mercado (ROLNIK, 1997, p.01). Nessa lógica, o cis-tema cria territórios onde a governamentalidade estrutura-se e age tendo como referência o masculino branco heterossexual. Maria Clara Araújo Sena ${ }^{2}$, uma das mulheres que compõem o trabalho cartografado ressalta que

O medo dessa estrutura regente e dominante, de nós bagunçarmos com o que alguns chamam de 'status quo', faz com que eles tentem cobrir nossa existência, apagar nossas memórias, não permitir que possamos nos representar. Afinal, quem foi eleito como 'normativo', acaba detendo o poder de escolher como o 'Outro' será representado (SENA, 2016, p. 12).

Bagunçar a lógica antropo-falo-ego-logo-cêntrica, sustentada por uma biopolítica da genitália cis-heteronormativa, torna ininteligível vetores vinculados ao pensamento e ao desejo que não se reconhecem nessa lógica. Trata-se da captura de vidas cuja diferença, afastados os estereótipos moralmente

\footnotetext{
${ }^{2}$ A travesti Maria Clara Araújo Sena é responsável pelo prefácio do livro "a história incompleta de Brenda e Outras mulheres", é pesquisadora de questões de gênero e sexualidade na educação e "é a 1 a transexual do mundo a atuar no combate à tortura em prisões, integrando o Mecanismo de Prevenção e Combate à Tortura em Pernambuco, órgão ligado à Secretaria de Justiça e Direitos Humanos, recentemente desmantelado pelo governo de Jair Bolsonaro (PSL). Em 2018, precisou se refugiar no Canadá por ter sido vítima de transfobia e racismo enquanto trabalhava no órgão" (FREIRE, 2019).
} 
construídos, não deve ser ou não merece ser retratada. Chico Ludermir (2017) afirma que

Não é por acaso que pessoas trans estão ausentes da maioria dos produtos de arte. Nada mais coerente com uma sociedade transfóbica do que o veto das representações e memórias das pessoas trans em livros, filmes e novelas. Pior: em alguns espaços, a representação da transexualidade vem carregada de estereótipos que reforçam estigmas.

Na contramão desta lógica, o processo artístico que permeia a obra de Ludermir, caracteriza-se pelo afrontamento a um cis-tema de arte que atua com base na inércia instaurada por um elitismo mundano de redução, muitas vezes, à lógica mercantilista e formalista, bem como anestesiadora que gera espectadores-passivos e confina a uma arte cis-têmica em esferas de especialização (ROLNIK, 2002).

O cis-tema, em conformidade com as relações de poder estabelecidas, produz as subjetivações tanto no campo das artes quanto da educação e encontra respaldo na ação antropo-falo-ego-logo-cêntrica componente da cultura de forma reativa que, apesar de albergar diferentes singularidades, nega as vivências subjetivas e as construções cooperativas e diversas (ROLNIK, 2016). Em entrevista dada a Breno Pessoa (2016), Francisco Ludermir ciente das relações de poder que atravessam todos os âmbitos da vida afirma:

Acho que a neutralidade é imobilizadora. De fato, tudo que a gente faz está engajado com o que acreditamos. Não dá para se despir disso. Acho que, na literatura e nas artes, a neutralidade vira o que é normativo. Sou contrário e descrente dessa neutralidade. Não corroboro, acho que a gente tem que acabar com isso e assumir nosso lugar político no mundo. Todos os produtos têm um papel político.

$\mathrm{O}$ autor, utilizando-se de uma caixa de ferramentas que atua junto a potências disruptivas vinculadas a táticas de re(x)istência ${ }^{3}$, visibiliza as vidas patrulhadas, enquadradas e capturadas pelas tecnologias de gênero (DI LAURETIS, 1994; LOURO, 2007). As capturas tentam cercear as linhas de fuga sob o verniz de neutralidade impossível. Em suas "notas do autor", Chico afirma que:

\footnotetext{
3 A palavra re(x)istência tem em sua construção o deslocamento da estrutura para marcar os processos de resistência e existência dos processos de sobrevivência de travestis e transexuais.
} 
"A História Incompleta..." têm vocação para resistência. Ou pelo menos parte deste princípio ético, assumidamente engajado. Não compactuo com o mito de uma literatura neutra. Não da forma como ela nos é enfiada goela abaixo. $\mathrm{O}$ sensível, em sua essência, de fato pode não ter cor, classe, gênero ou orientação sexual, mas essa literatura dita neutra escolhe muito bem seus temas e a quem deseja servir (LUDERMIR, 2016, p. 17).

Mapear os desassossegos e os descostumes gerados pelos percursos insólitos que compõem a obra "que tem vocação para resistência," nos remete também à análise das intervenções de artistas como as de Lygia Clark, na voz de Rolnik (1999; 2002), de Caio Fernando Abreu (1990) e Fernando Pessoa (1992), ou a liberdade de corpos em fotógrafos como Nan Goldin (YAHN, 2017), Bettina Rheims (PACCE, 2016) e Wolfgang Tillmans (MACLENNAN, 2017). As expressões artísticas, assim como a obra de Ludermir, se manifestam como potência para identificarmos agenciamentos que envolvem os "afectos" e "perceptos" que compõem os corpos quando entram em contato com o mundo (ROLNIK, 2006).

Como nosso método é cartográfico e é da ordem dos descostumes", queremos encontrar Chico Ludermir em seu processo, buscar pistas do "meio caminho", da beira da estrada ${ }^{5}$. Logo, acreditamos traçar uma metacartografia, cartografia da cartografia, visto que, por mais que Ludermir não tenha adjetivado seu processo dessa forma, inferirmos que ele o fez, pois visibilizou linhas de intensidade, fabulou afetos incitando-os a transitarem, criou e desmanchou mundos (ROLNIK, 2014).

\section{EU VIM DE INFINITOS CAMINHOSE OS MEUS SONHOS CHOVERAM LÚCIDO PRANTO PELO CHÃO ${ }^{6}$}

Buscar o meio do caminho, analisar o processo criativo, sem ter intenção e mesmo condições mínimas de críticos literários, visto não termos formação

\footnotetext{
${ }^{4}$ A cartografia dos descostumes emerge de uma analítica da educação pensada enquanto ethos filosófico que incorpora para seu campo de tematizações as desterritorializações e as "novas" subjetividades, a fim de perceber o exercício de práticas de liberdade envolvendo os corpos abjetificados pelo poder constituído, através de modos de pesquisa que se interessam pelas micropolíticas cotidianas.

${ }^{5}$ Seu trabalho torna-se nosso ponto de partida que deverá culminar com o retrato em $3 \times 4$, a ser apresentado formalmente em uma tese que se encontra em construção.

${ }^{6}$ MEIRELES, Cecília. Viagem. Global Editora e Distribuidora Ltda, 2019.
} 
para este tipo de análises, distanciou-se dos propósitos que elencamos. Girávamos em torno do processo de buscar pistas, aprender, recortar e encontrar os caminhos e linhas propostos pelo autor para, como educadores que somos, buscarmos pensar os processos educativos ali contidos.

Francisco havia publicado no caderno de Suplemento da Companhia Editora de Pernambuco ${ }^{7}$ uma espécie de relatório detalhado intitulado "Encontros que tornam bela a incompletude". Neste relatório, encontramos ressonâncias do corpo vibrátil anunciado por Rolnik (1999, p. 32), um corpo constituído de uma consistência subjetiva feita de composição sensível, que se cria e recria impulsionado pelos pedaços de mundo que o afetam: "aquilo que em nós é ao mesmo tempo dentro e fora: o dentro nada mais sendo do que uma filtragem seletiva do fora operada pelo desejo, produzindo uma composição fugaz". Tal corpo, ao ressoar, estendia-se e atingia-nos em cheio.

Corroborando com nossas intenções, Ludemir havia criado uma espécie de diário com registros que se assemelham a cartas enviadas para si mesmo. O dia 18 de março de 2013 marca o início dos escritos nos quais é possível identificar o quanto o caminhar do artista foi se fazendo no próprio andar, permitindo dessa forma, um afetar-se pelas linhas que se instituíam a cada momento.

Entre pesquisa, entrevistas, fotos, edição e diagramação, estimava terminar em três meses e meio. Rio internamente diante da impermanência e subestimação do trabalho: nem 10, mas, sim, 11; nem reportagens, mas, sim, contos de não ficção. Ao invés dos três meses e meio, mais de três anos até a publicação, no Rio de Janeiro, em novembro de 2016. Anne me fez aumentar o número de histórias em um, porque desistiu de desistir. Somente quando o original estava em minhas mãos, recebi o seu aceite [...]. Volto aqui ao meu "e-mail-diário" em 10 de agosto de 2013: "As histórias que eu escutei até agora são fascinantes" (LUDERMIR, 2017).

Além dos movimentos, alterações de rotas, Francisco relata que a mudança do formato de reportagens para o de contos aconteceu naturalmente, à medida em que passou a desacreditar na noção de verdade (LUDERMIR, 2017). Talvez, estivesse presente a ideia de que "a verdade é aquilo que dizemos ser verdadeiro - que equivale a dizer que as verdades não são des-

\footnotetext{
7 Responsável pelas publicações oficiais do Diário Oficial do estado entre outros elementos e publicações culturais.
} 
cobertas pela razão, mas sim inventadas por ela". (VEIGA-NETO, 2003, p. 108-109). Dessa premissa, emerge o abandono da crença em uma linguagem que seria capaz de representar o mundo "tal qual ele é", ou seja, a linguagem como uma tradução literal e isomórfica do mundo.

Francisco afirma que "o próprio ato de lembrar é uma experiência narrativa de criação. Recontar e encadear ideias muitas vezes se torna tão mais real quanto mais é inventado" (LUDERMIR, 2017). Narrativizar, em toda sua obra, parece ser um deslocamento linguístico fundamental por tornar verbo a ideia de se recontar através de técnicas que podem ser tidas como vinculadas ao cuidado de si, como nos ensinou Foucault (2004).

Assim, as mulheres biografadas acessam o processo de subjetivação e de construção da mulheridade através da desconstrução e reconstrução das memórias e trazem a transformação de subjetividades através do posar, relatar, performar, recontar, reler-se, rever-se e fabular-se. Em entrevista dada a Breno Pessoa (2016), Chico Ludermir retoma a temática:

Acho que o processo de relatar sua própria história e a construção da memória traz uma certa ficcionalização. Quando você vai relembrando algo e encadeando fatos, há um ato criativo, criador, também quando se escuta e/ou se propõe a recontar uma história. Alguns elementos são impossíveis de serem relatados com precisão e elas também estão, de alguma maneira, recriando. Construí o texto a partir de uma sensação e do desejo de representação possível (PESSOA, 2016).

Assim, houve construções, desconstruções, encontros e desencontros em um agenciamento incorporado na obra de Ludermir e que se instituiu a partir dos "contos de não ficção" (LUDERMIR, 2017), cuja presença do autor não tinha possibilidade de eliminação

Não estou dizendo com isso que abandonei o compromisso com o vivido por elas, mas que assumi a tarefa de criar em conjunto. Com isso, preciso dizer que todos os contos foram lidos por elas em primeira mão e que tudo que me foi pedido para ser alterado ou omitido foi acatado" (LUDERMIR, 2017, grifos nossos).

Assim, no trabalho de Chico Ludermir há discursos dentro de discursos, palavras que são escolhidas e que são os elementos do presente delineamento da cartografia por ele realizada. Essa, situa-se no campo de suas desterritorializações cujas projeções afetivas atravessam o cis-tema, rompendo o que é tido como comum e normal. Outrossim, o autor, o cartógrafo, os leitores do livro 
e até as próprias mulheres expostas em sua nudez de alma nos movimentos da obra possuem, cada qual, interpretações de si e dos outros que fogem a uma ética retida no "bem" e a uma estética limitada ao "belo", pois estetizar levar-nos-ia ao ponto comum que poderia constituir uma possibilidade de libertação através da busca por um estilo em harmonia com os diversos domínios (KRUTZEN, 2011).

O processo de desenvolvimento dos trabalhos deixa claro um estilo cartográfico permeado por heterocronias e heterotopias. O próprio autor identifica três movimentos (o coletivo, o individual e o universal) em sua cartografia de desejos de mulheres trans, embora, como dito anteriormente, em nenhum momento esteja explícita sua condição de cartógrafo.

\begin{abstract}
As heterotopias, neste caso, representam relações sociais e de poder espacializadas, desviantes ou não, transgressoras ou não, que questionam estruturas profundamente enraizadas. Contudo, apresentando-se como formas espaciais alternativas ou bastante específicas, nunca deixando de estar ligadas a recortes e períodos de tempo, a conjunturas históricas singulares e, logo, não deixam de ser, também, heterocronias (FOUCAULT, 1967, p. 417).
\end{abstract}

O movimento coletivo político atua no alinhavar de uma colcha de retaIhos, considerada por ele como elemento de "um mesmo estrato social: muIheres trans e travestis"(LUDERMIR, 2016, p. 18) consideradas em relação a experiências comuns de discriminação, preconceito, violência e marginalização.

Francisco foge do lugar comum que se destina a estes corpos: a prostituição, a criminalidade e as doenças venéreas (em especial o HIV), pois nega-se a retratá-las a partir do "lugar que lhes parece reservado ou determinado" (LUDERMIR, 2016, p. 18), como se essas circunstancias fossem uma condição determinante. De forma contrária, propõe em sua escrita poética, um anti-destino ao que lhes torna estigmatizadas. Nas palavras de Bruna Benevides ${ }^{8}$ (2016) as mulheres "foram retratadas enquanto seres humanos de fato, tão diferente de textos outrora escritos sobre nossas vidas. Entrelaçadas, como uma colcha de retalhos que, em muitos momentos, se confrontam exatamente com as mesmas violências, perspectivas, necessidades e possibilidades".

\footnotetext{
8 Travesti, militar, primeira mulher transexual a receber o Prêmio Mulher Cidadã da ALERJ. Militante LGBT e Ativista Transfeminista. Coordenadora do Prepara Nem Niterói. Presidenta do Conselho Municipal LGBT de Niterói, Secretária de Articulação Política da ANTRA e Coordenadora GTN.
} 
O segundo movimento, que é estético, trata de uma pragmática da sismesmidade por articular a estética da existência aos devires minoritários em experimentações desviantes e desterritorializantes. Cada mulher narrada apresenta sua dinâmica de constituição, o fato de estabelecer-se mulher para si e para a sociedade. Apesar de este ser um movimento comum a todas, existe:

A singularidade de cada vida. Por mais que exista, sim, um tanto de padrão, há um outro tanto muito maior de nuances que permitem aprofundar em cada uma delas sem repetições. Cada personagem deste projeto colabora com sua história, com sua imagem, com sua voz (LUDERMIR, 2016, p. 18).

O terceiro movimento envolve o nomeado movimento-ético. Esse teria a possibilidade de construção de uma liberdade ética que incita o "outro" para uma condição de aproximação e retração da segregação, mesmo que isso ainda ocorra de uma maneira ainda utópica. Frente a esses movimentos, que perpassam a ficcionalização das narrativas, inferimos a existência de uma cartografia que se move, que se faz ora densa, ora rarefeita. Trata-se de linhas de força, que dobram e se desdobram sobre o sujeito e em efeito, criam "Encontros que tornam bela a incompletude" (LUDEMIR, 2017).

\section{DOS ENSAIOS FOTOGRÁFICOS À POESIA POLÍTICA}

A cronologia do processo criativo de Francisco Ludermir é marcada por um processo de gestação afetada por uma "virada sutil na produção" (LUDERMIR, 2016, p. 18). A primeira fase identificada de produção da obra de Chico Ludermir durou dois anos e exigiu do fotógrafo-jornalista-escritor uma imersão profunda no campo de estudo que orbitou as vivências de muIheres. Esse movimento fez-se necessário para a ficcionalização das histórias capturadas através de entrevistas gravadas, transcritas e de ensaios fotográficos em preto e branco realizados entre os anos de 2013 e 2015 (LUDERMIR, 2016, p. 17; G1, 2015; BRASILEIRO, 2015).

No texto, ao procurar Mariana para ouvi-la, descreve a experiência vivida na Favela do Pilar (Recife Antigo), "Já era fim de tarde e o chão de terra ficava ainda mais alaranjado no Pilar. Na sombra de uma casa quase em ruínas, uma moça chupa uma manga com um dedo entortado por golpes de capacete. Ao lado outros caroços, já sem polpa" (LUDERMIR, 2016, p. 96). 
Posteriormente, verifica-se a presença do autor, não só como aquele que descreve a cena, mas que se mistura a ela: "Desviamos de algumas poças de lama juntos. Comemos mais uma manga e seguimos com uma trouxa de roupa que ela pegou para lavar. Assim consegue o dinheiro para o hoje. No amanhã, só pensará quando acordar. Vai vivendo um dia por vez" (LUDERMIR, 2016, p. 98).

Após essa imersão inicial, a costura do trabalho fotográfico e da escrita do que inicialmente havia sido projetado para serem reportagens, se encaminhou para confecção de um livro coletando os dados trazidos nas falas e fotos das mulheres, em tom biográfico. Assim, os ensaios fotográficos vieram em conjunto com o processo criativo do livro e compõe sua estrutura. Esses ensaios vieram da ideia original do projeto do Núcleo Integral de Saúde Coletiva da Universidade de Pernambuco - NISC, mas foram tomando outras formas, outros desenhos, a partir dos encontros realizados, razão pela qual inferirmos existir uma cartografia impulsionada pelos desejos e encontrada na forma de confeccionar a obra.

Em entrevista dada a jornalista Isabelle Barros (2015), Ludermir fala de suas transformações, resultado de sua estreita proximidade com as mulheres pesquisadas: "Antes desse trabalho, eu também partilhava, de certa forma, de uma visão marcada pelos preconceitos da sociedade com relação às mulheres trans. Os ensaios partiram muito da história de vida delas e foram pautados a partir do que fui descobrindo" (BARROS, 2015).

Ilza Matias de Sousa (2011, p. 166), ao discutir algumas literaturas menores de singularidades selvagens como as de João Gilberto Noll, de René Magritte, de Lewis Carroll e de Clarice Lispector, afirma que essas afetam "a relação sujeito e objeto do conhecimento racional, a abordagem das singularidades selvagens exige tocar a exceção, deixar-se extravaganciar, haver-se com o estranho, dar-se à dissipação. A exceção é da ordem da exclusão - exclusão da regra, norma geral".

A obra de Ludermir, adjetivada aqui como menor, periférica, marginal, com uma exterioridade selvagem, que não se deixa capturar ou integrar, é singular e carrega a propriedade de dissipar-nos. O próprio autor aponta nos traços de seu texto "formatos intencionalmente híbridos (o hibridismo se dá como continuidade das reflexões sobre certos limites da realidade e da cons- 
trução. A vida é a arte e a própria memória é construída em ato e performance do cotidiano)" (LUDERMIR, 2016, p. 17).

As narrativas e os textos instigam-nos a perceber que existe um entremeio situado entre objetos e sujeitos, contudo não se está nem em um lugar e nem em outro, mas em algo inominável que se subtrai ao controle e nos leva a olhar para os abismos (SOUSA, 2011). Acompanhando Deleuze (2010, p.35), diríamos que "é no meio do turbilhão que há o devir, o movimento, a velocidade, o turbilhão. O meio não é uma média, e sim, ao contrário, um excesso. É pelo meio que as coisas crescem".

Assim, a obra em si apenas tangencia o autor, sobrelevam-se as potências dos corpos nela contida de imediato. Foucault (2001, p. 72), em Ditos e Escritos IV, indica que "o que é preciso fazer é prestar a atenção no espaço esvaziado pelo desaparecimento do autor; seguir atentamente a repartição das lacunas e das falhas, e espreitar os lugares, funções livres que esse desaparecimento faz aparecer".

Nesse hiato, que esvazia o tempo, faz ficção das narrativas. Em fala videografada de Brenda Bazante (2016), mulher que compõe o título da obra, no curta metragem de sua biografia, desenha o estilo de Ludermir no livro:

[...] você também associou essa situação em particular a um outro período criando dentro da biografia em si uma nova situação, juntando nomes a tempos diferentes. Tratando em particular de uma situação que foi muito delicada. Eu me emocionei muito porque realmente parece que eu fiz uma viagem para aquele momento (grifo nosso).

Eugênia Correia Krutzen (2011) discorre que para um trabalho literário tornar-se um acontecimento faz-se necessário o entendimento do autor como aquele que "se arvora ao perder essa autonomia do dizer, para em seguida recuperar na forma de cintilações". Nesse sentido, Bruna Benevides (2016) torna translúcida sua opinião sobre a obra:

Em muitos momentos fiquei feliz, triste, excitada e algumas vezes senti a dor de cada uma, especialmente por ser uma mulher trans - com identidade travesti, que a cada linha, página e capítulo se enxergava ali. Nua, exposta na minha mais interna singularidade. Tendo meu corpo e minha vida escancarados diante do alcance que os textos poderiam causar. Diante de toda mudança e ressignificação, desconstrução e construção que ele poderia promover. Cada pessoa ali era um pouco de mim e eu um pouco de cada uma delas. (...) tudo isso e 
muito mais é dito de uma forma muito peculiar. Sublime. Intensa e honesta (BENEVIDES, 2016).

\section{IMAGEM-CRISTAL: curtas-metragens de vivências trans}

A forma de estruturação dos curtas-metragens não se desvincula da estética e pragmática da simesmidade encontradas na construção do livro, dos ensaios fotográficos e da intervenção artística, que será analisada posteriormente $^{9}$. O passado narrado, muitas vezes na terceira pessoa do singular, indicava que aquela mulher ou aquele menino afeminado, aquele amor que faceia uma autodestruição, retratava outra pessoa. Assim, o pronome pessoal empregado sinalizava o distanciamento desejado entre a forma desejada e a representação ali exposta.

Ludermir afirma que a criação dos vídeos ocorre da seguinte forma: "em um dos momentos, elas entram em contato pela primeira vez com os textos que fiz. É como um exercício em que elas recontam suas histórias, comentam o que querem mudar, por exemplo. É como se elas estivessem colocando em xeque a representação que é feita delas e meu papel como autor" (BEZERRA, 2015).

Foucault utiliza a experiência do espelho para que se compreenda meIhor a ideia da Heterotopia. Aqui, os vídeos biográficos feitos em mais de um momento, as lidas, relidas, revisões, atualizações de situações havidas depois de o livro estar quase pronto compreendem uma experiência semelhante a do espelho. Essa inferência se dá, pois se trata de uma experiência mista, conjugando o lugar sem lugar de um vídeo lançado na internet (espaço virtualizado), que reflete a elas mesmas com a existência da vida real. Compreende-se, dessa forma, em um mesmo lugar e tempo, a realidade e a fabulação refletidas (CASTRO, 2015).

Os vídeos mostram várias realidades, intervalos de tempos com várias situações ligadas a mesma pessoa. Há ocasiões em que a edição do curta-metragem divide a tela entre dois momentos de vida diferentes que refletem

\footnotetext{
9 Os curtas-metragens em vídeo foram disponibilizados na web pelo autor e foram realizados em parceira com a FUNDAJ com apoio do Laboratório de Imagem e Som do departamento de Comunicação da UFPE. A Linha documental usada por Ludermir inspirou-se no filme Jogo de Cena (2007), de Eduardo Coutinho (BEZERRA, 2015).
} 
a mesma mulher. Exemplo disso é Rayanne, uma mulher abandonada por ser transgênera, que, posteriormente, reata seu namoro após seu companheiro ter resistido aos tentáculos da cis-heteronormatividade. Assim, o intervalo temporal proposto pelos curtas-metragens consiste:

[...] entre a percepção e a ação pode ser apreciado como momento da indeterminação. É nele que hesitamos, escolhemos, gestamos nossas escolhas com a totalidade de nosso passado. Nele também assistimos à gestação de um novo desejo, como também à emergência das nossas livres decisões. Nele, enfim, intuímos a atividade da criação quando, na pausa indispensável que exige o pensar, vemos emergir, com ritmo próprio, uma ideia nova, uma ideia tempo que será desenvolvida em uma atividade criativa (MACIEL, 2007, p. 57).

Maria Clara (SENA, 2016) comenta que esses entre-lugares que habitam simultaneamente o passado e o presente geram incômodos. Exemplo disso reside no fato da imagem-tempo necessitar o nome de batismo. No entanto, fica evidenciado, no material analisado, tratar-se de uma dor necessária, como a dor de um parto. Dores do parto que fazem parte da pragmática da simesmidade.

Você também toca no meu nome Roberval que hoje ninguém me conhece por este nome. Não me faz mal, como eu disse... eu estou... eu passei por uma fase da vida que coisas do meu passado não me incomodam. Eu sei que este Roberval como as torturas psicológicas e físicas que eu sofri me fez ser essa pessoa que eu sou hoje. Também sei o "ele" aí porque ele (o autor) colocou. Você não está jogando palavras ao vento.

Destacam-se, assim, vários elementos de violência e de silenciamento da voz e do grito das mulheres que, em tela, se acoplam em agenciamentos produzidos pelo inconsciente colonial capitalístico de abjetificação do corpo trans. Rayanne (2016), no curta metragem de sua biografia, fala da mesma condição ao relatar que:

Eu acho que a princípio, no início deste trabalho, uma coisa que era meio tabu para mim era citar o meu nome... o meu nome de batismo, de registro, mas hoje eu vejo que é importante. É importante que essa parte seja tão frisada quanto as outras. Por que isso mostra que eu sou tão forte quanto as pessoas imaginam. Que eu posso deixar claro ali o meu nome de batismo quando (...) hoje eu sou Rayanne Romanelli.

Encontram-se nos vídeos imagens que, vistas de forma isolada, apenas mostram mulheres esperando, pensando, mas acrescido ao som, ouve-se as 
vozes das mesmas se narrando, seja em leituras de trechos de suas próprias biografias, seja na complementação de detalhes que não couberam no texto ou que surgiram posteriormente a sua edição.

Em outros vídeos, como o de Luana, que apesar de performar mulher, diz que sabe que jamais o será. No vídeo, ela aparece reflexiva e se não houvesse som algum, a imagem mostraria que Luana estava sem nada a dizer, apenas aguardando para ser descrita. Mas a voz da narradora de sua história é a dela própria, corta esse momento.

Nesta análise, faz-se importante aproximarmos a ideia dos curtas-metragens à imagem proposta por Deleuze (1990 apud DINIS, 2005, p. 73) ao falar sobre o cinema: "trata-se da emergência de situações ópticas e sonoras substituindo situações sensório-motoras enfraquecidas. São produzidas situações de visibilidade e audição que não derivam de ações, nem necessariamente se prolongam em ações". Os curtas-metragens trazidos neste trabalho falam individualmente de cada mulher enquanto unidade de vida através da produção de suas imagens-cristal.

O que constitui a imagem-cristal é a operação mais fundamental do tempo: uma vez que o passado não se constitui depois do presente que ele foi, mas ao mesmo tempo, é preciso que o tempo se desdobre a cada instante em presente e passado, que diferem um do outro em natureza, ou, o que dá no mesmo, desdobre o presente em duas direções heterogêneas das quais uma se lança para o futuro e a outra cai no passado. É preciso que o tempo se cinda em dois jatos dessimétricos, um dos quais faz passar todo o presente, e outro conserva todo o passado. O tempo consiste nessa cisão, é ela, é ele que se vê no cristal (DELEUZE, 1990, p. 108-9).

Em várias passagens dos curtas, e na integralidade do curta sobre a biografia de Luana Rodrigues, as leituras do expectador ocorrem sem palavras, só pelos movimentos e linhas encontrados nas imagens do vídeo. Apesar das mulheres biografadas não se encontrarem entre si diretamente nos curtas, estes encontros acontecem em virtude de cada narrativa estar marcada por desejos, desconstruções e por um nascer mulher que parece pertencer a um corpo ainda por vir. Assim,

[...] é a partir da escuta do corpo vibrátil e suas mutações, que o artista, desassossegado pelo conflito entre a nova realidade sensível e as referências antigas de que dispõe para orientar-se na existência, sente-se compelido a criar uma 
cartografia para o mundo que se anuncia, a qual ganha corpo em sua obra e se autonomiza de sua pessoa. Através da prática artística, atividade de semiotização da experiência humana em seus devires, a vida afirma-se em seu erotismo criador, gerando novas paisagens existenciais (ROLNIK, 1999, p. 3).

Encontramos tanto no curta-biográfico de Maria Clara Araújo de Sena como na paisagem desenhada no livro produzido por Ludermir o encontro de realidades. Na "História Incompleta...", o autor também acompanha Maria Clara no seu dia a dia, seus hábitos, costumes... e a violência diária que sofre. Chico Ludermir (2016, p. 109) traduz o que viu na situação da seguinte forma:

Na Rua da Imperatriz, Maria Clara ouviu a primeira gracinha da noite. Veio de um menino de uns quinze anos, que andava em grupo com outros três. "Queres essa morena pra tu?", perguntou ao colega em tom de deboche. Na ponte velha, um senhor barrigudo não precisou dizer. Apenas olhou com um desprezo firme Clara se aproximar, cruzar e passar. Já entrando na estação Central do Recife de metrô, ela ouviu mais uma, desta vez de um vendedor ambulante. "Essa daí vem com um brinde", gritou para quem quisesse ouvir. "O brinde é a sua mãe", respondeu, sem olhar para trás, misturando-se à confusão do centro. Uma multidão se empurrava disputando espaço em um dos vagões rumo a Camaragibe. Mesmo assim, ela não passava despercebida. 1,90, negra, cabelos cheios, óculos de armação grossa, Clara prendia olhares, despertava desejo, desdém, comentários. Tinha sido assim por todos os lugares que passava desde o mais longe que podia resgatar na memória.

Por outro lado, o que sente as mulheres retratadas nesta obra nem sempre está a mostra. Maria Clara (2016) comenta que a experiência trouxe percepções e sentimentos que a inquietaram. Ela reconhece sua rotina na situação dos apedrejamentos sociais de todo dia. Assim, o que para o mundo é um descostume, para ela são enfrentamentos diários. As fendas da cidade perpassam aquela mulher ou são ela:

Pois é, essa parte mostra para você os desafios que todo dia a gente passa... de graça, de olhares... eu fico até feliz que neste dia que você estava comigo não ter tido momento de agressão física. Porque já tive que partir para briga por defesa. E nesse momento eu estava meio que frustrada de estar com você porque para mim é normal. Era o trivial: feijão, arroz e charque. Daí eu estar com você... eu estava meio que te protegendo para que você não visse aquilo tudo. Você é uma pessoa que tem o seu mundo e estava no meu mundo. Eu pensei: isso ele não pode ver. Isso ele não pode sofrer... foi assim.

A compreensão das imagens-cristal nas biografias videografadas exigiu de nós uma escuta que só o corpo vibrátil e suas mutações permitem: a cria- 
ção de uma cartografia entre a nova realidade sensível e as referências antigas. Essas exportaram, tornaram exógenas e trans-emergiram a experiência humana em seus devires por meio da semiotização.

Percebe-se que os entre-lugares descritos como heterotopias nos ensinam que as imagens-cristal atrelam passado, presente e os intervalos entre eles às várias realidades e fabulações que geram incômodos e afrontam os agenciamentos comuns ao inconsciente colonial capitalístico que abjetifica o corpo-trans, enquanto unidade de vida, mas que não consegue conter os desejos e deslocamentos do ser/tornar-se mulher. Só assim pudemos compreender o universo vivido nos curtas-metragens que promovem a estética e a pragmática da simesmidade.

\section{INTERVENÇ̃̃ES ARTÍSTICAS: performances no/do passado}

A intervenção artística contou com articulação de novas parcerias, a Fundação Joaquim Nabuco- FUNDAJ- e a Universidade Federal de Pernambuco - UFPE - que permitiu um novo "pensar", a partir de variações no corpo vibrátil do autor. Realinhou-se o eixo da discussão para uma análise cartográfica dos desejos, no momento em que cada uma faz o processo de floração de realidade enquanto mulher.

Seja qual for o meio de expressão, pensamos/criamos porque algo de nossa vida cotidiana nos força a inventar novos possíveis que integrem ao mapa de sentido vigente, a mutação sensível que pede passagem - nada a ver com a demanda narcísica de alinhar-se à "tendência" do momento para ganhar reconhecimento institucional e/ou prestígio midiático. A especificidade da arte enquanto modo de produção de pensamento é que na ação artística, as transformações de textura sensível encarnam-se, apresentando-se ao vivo. Daí o poder de contágio e de transformação de que é potencialmente portadora tal ação: é o mundo o que ela põe em obra, reconfigurando sua paisagem (ROLNIK, 2007, p. 104).

Nesse ínterim, surgiu um convite dos pesquisadores, Moacir Tavares Rodrigues dos Anjos Junior ${ }^{10}$ e da Coordenadora de Artes Visuais Bruna de

\footnotetext{
${ }^{10}$ Moacir Tavares Rodrigues dos Anjos Junior possui graduação em Economia pela Universidade Federal de Pernambuco (1984), mestrado em Economia pela Universidade Estadual de Campinas (1990) e doutorado em Economia - University College London (1994). É Pesquisador da Fundação Joaquim Nabuco desde 1990 e Professor Colaborador no Programa de Pós-Graduação em Artes da Universidade Federal do Ceará desde 2013. Foi Diretor do Museu de Arte Moderna
} 
Sousa Pedrosa Paes, ambos funcionários da Fundação Joaquim Nabuco, para adaptação das fotos e dos textos para desenvolver uma intervenção artística, que ficou em cartaz de 23 de julho à 24 de agosto de 2015 (PESSOA, 2016).

A articulação da resistência em espaços estatais como universidades, fundações públicas e equipamentos culturais estatais pode ser vista como elemento de discursos ativos que se contrapõem a uma micropolítica reativa, dispondo a possibilidades para outras estratégias, pois,

é preciso admitir um jogo complexo e instável em que o discurso pode ser, ao mesmo tempo, instrumento e efeito de poder, e também obstáculo, escora, ponto de resistência e ponto de partida de uma estratégia oposta. O discurso veicula e produz poder; reforça-o, mas também o mina, expõe, debilita e permite barrá-lo (FOUCAULT, 1988, p. 95).

O projeto Arte, Reforma e Revolução (FUNDAJ, 2015) tinha como proposta de desconstrução manter o prédio da Fundação Joaquim Nabuco "vivo" durante a reforma física do edifício Ulysses Pernambucano, construído, na década de 1950, no Derby. A estratégia cultural propunha debates ligados à resistência, como "Cidade e Resistência", "Arte e Resistência" e "Política e Resistência", bem como albergava exposições, projeções nas ruínas da obra, visitas guiadas pela reforma e intervenções artísticas dentro da própria obra. Na esteira desses debates e exposições, emerge a intervenção artística de Chico Ludermir que foi nominada: "Mulheres: o nascer é comprido".

Nesse mote, articular a reforma do prédio aos ensaios fotográficos, ao livro e aos vídeos trouxe à baila a relação entre o corpo e o espaço construído. Assim, uma das iniciativas foi permitir que os curtas-metragens fossem projetados nas paredes em reforma (BEZERRA, 2015). Ademais, vinte fotografias tornaram-se imagens-revolução, sendo dez delas dos arquivos pessoais das mulheres que compõem a obra em momentos nas quais ainda eram identificadas como do gênero masculino; e o restante, também publicadas no livro, oriundas dos ensaios fotográficos relacionados ao projeto.

Aloísio Magalhães entre 2001 e 2006 e Pesquisador Visitante no grupo de pesquisa TrAIN - Transnational Art, Identity and Nation, na University of the Arts, em Londres, entre 2008 e 2009. Tem experiência na área de Artes Visuais, com ênfase em Teoria da Arte, atuando principalmente nos seguintes temas: arte brasileira, arte e política, cultura contemporânea e globalização. Foi curador da 29a Bienal de São Paulo (2010) (CNPQ, 2019). 
As imagens em preto e branco foram inicialmente impressas em azulejo e sofreram intervenções (tanto as do acervo pessoal quanto as dos ensaios do autor) pelas próprias mulheres, uma vez que a ideia principal girava em torno das noções de exploração e de transformação corporal vividas por transexuais. $\mathrm{O}$ fato de terem sido impressas em azulejos permitia que elas pudessem "alterar", "mexer" em seus passados, de forma gráfica. Nesse ínterim, a imagem deixava de ser estática para permitir uma alteração dinâmica do passado-presente, situando-se no meio, no entre-lugares (BRASILEIRO, 2015; G1, 2015; BARROS, 2015).

O trabalho fronteiriço da cultura exige um encontro com o "novo", como ato insurgente, e não parte do continnum do passado e do presente. Gera uma produção artística que não apenas retoma o passado - causa social ou precedente estético -, mas o renova, refigurando-o como um "entre-lugar" contingente, que, além de inovar, interrompe a atuação do presente. $O$ "passado-presente" torna-se parte da necessidade (e não da nostalgia) de viver (BHABHA, 2003, p.27, grifos nossos).

A impressão das fotos em azulejo facilita o processo de alteração das imagens, uma vez que permitiu a algumas mulheres desenharem sobre seus corpos e escreverem sobre suas experiências. Além disso, foram acrescidos textos do autor às imagens, mostrando a intrínseca relação do autor com as mulheres. Depois, os azulejos com as inserções foram fixados com cimento às paredes que estavam em processo de restauro (BEZERRA, 2015). Dentre os textos acrescidos temos:

\footnotetext{
"Nascer mulher, afinal, para muitos não é fato imediato, mas processo comprido o bastante para durar uma vida inteira. E que, mesmo assim demorado, é para muitas incontornável". "Que o amor oriundo do nascimento, quando o sexo biológico é revelado, permaneça em nossos pais após revelarmos nossa identidade de gênero. Afinal, sendo meninas ou meninos continuamos sendo filhos ou filhas". "Não se nasce mulher, nos tornamos! O amor de minha mãe foi essencial para minha realização. Nasci num corpo que não me pertencia, modifiquei e me realizei" (grifo nosso).
}

As mulheres retratadas, rejeitadas por serem o que são, ditas homens ao nascer, explodem em existências e resistências. Alexandre Filordi de Carvalho (2016) afirma a importância de discorrermos sobre novas formas de experiências, que realcem subjetividades ativas que libertem concepções e conduta oriundas de uma individualidade imposta. Nesse sentido, Maria Clara de Sena, em entrevista sobre a intervenção artística, afirma que: 
No primeiro momento foi tranquilo. Quando ele falou sobre a ideia de mostrar as fotos do passado, eu até pensei um: 'Eita...'. Mas sabia da importância de colocar na exposição porque é a minha história. Depois fui ficando mais à vontade, quando gravamos o vídeo também, começou a fluir a conversa da nossa vivência.

São devires que transbordam daqueles pelas quais transpassam, pois cada narrativa possui seu conatus. Bons e maus encontros, mas sempre corpos políticos de resistência e força. Maneiras fabuladas de encontrar o passado, refazê-lo. Histórias de ódio e violência que dão a impressão errônea de que as singularidades se aproximam das leituras cartesianas e estruturalistas de uma "identidade universal".

Robustecendo essa ideia, registramos que a estreia da intervenção artística foi marcada pela composição de uma mesa redonda com o curador Moacir dos Anjos e a professora do Departamento de Comunicação Social da UFPE, Cristina Teixeira Vieira de Melo, além do próprio Francisco Ludermir (BRASILEIRO, 2015). O lançamento do livro só ocorreu no ano de 2016, dia 12 de novembro, na Festa Literária das Periferias (FLUPP), na Cidade de Deus, no Rio de Janeiro, e no Recife, no dia 10 de dezembro (PESSOA, 2016). Importante registrar a distribuição de exemplares e a entrada no evento gratuita para mulheres trans e travestis.

Há uma potência cartográfica no nascer deste artigo que se inspira numa função-artística que é tão cumprida quanto o nascer mulher dos devires transexuais que vimos aqui. Nossa cartografia do descostumes visa analisar os processos educativos que estão na rotina, no dia a dia, no habitual e cotidiano de mulheres transexuais construídas sem pena, com força e violência. Não são existências que sejam aceitas, percebidas facilmente ou mesmo que se possa impor, uma vez que ainda são frontalmente abjetificadas. Ao mesmo tempo, rompem estruturas (im)postas à partir das bordas e margens do cis-tema educacional.

Esse cis-tema espalha-se, envenena toxicamente e bloqueia através de estratégias que tentam limitar os corpos e os fluxos de desejo. Contudo, as potências, o desejo, as micropolíticas ativas estabelecem-se em agenciamentos complexos e múltiplos como raízes que emergem produzindo conexões e em direções imprevisíveis ou ainda não existentes nos espaços que interagem com as vidas, seja na escola ou fora dela. 


\section{CONCLUSÃO}

A cartografia aqui proposta trouxe a possibilidade de gerarmos um mapa que espelhasse os fluxos contínuos contidos na Cartografia de Chico Ludemir, ou seja, nos depararmos com uma metacartografia (cartografia da cartografia). Mapear os descostumes, agenciamentos que envolvem os "afectos" e "perceptos" que se inspiram numa função-artística e no nascer mulher dos devires transexuais, nos trouxe a ideia de várias educações insurgentes que eclodem como acontecimento a partir de agenciamentos artísticos, culturais e educacionais. A problemática surgiu da possibilidade de que elementos artísticos em agenciamento constituíssem estratégias de re(x)istência no acontecimento educação. Observamos que apesar do inconsciente colonial capitalístico, insurgem linhas de fuga e novos espaços de resistência e invenção.

O primeiro movimento, que buscamos desenvolver para alcançarmos a reposta à pista proposta, mapeou a molecularidade observada nas linhas de fugas a partir das subjetividades do autor e de seu olhar vibrátil. Percebemos uma tecnologia educacional acionada a partir do cuidado de si em sua estilística política, estética e ética da existência.

Observou-se uma forma de educação paralela e rizomática- que fugia a estrutura totalizante e universalizante de uma pedagogia maior, uma vez que o autor se transforma na obra ao mesmo passo em que aprende.

A partir desse movimento de consciência de um lugar de fala e de um aprendizado recíproco, surge o segundo movimento que mapeou a molecularidade observada nas linhas relacionadas as personagens e da relação delas consigo próprias no posar, relatar, performar, recontar, reler-se, rever-se e fabular-se. Percebemos que a desconstrução e a reconstrução de suas memórias permitiram que elas operassem sobre os assujeitamentos vivenciados, dando visibilidade aos modos de subjetivação que os sustentam. Podemos inferir novos caminhos foram abertos por corpos que assumiram a politicidade de seu ser.

O terceiro movimento tratou do mapeamento de parte da obra de Francisco Ludermir. Essa foi entendida como conjunto artístico identificado nos ensaios fotográficos, na poesia política, na imagem-cristal dos curtas-metragens, na intervenção artística e no livro. Nossa escrita tentou captar 
os elementos das situações descritas para além das vivências e avançou para aspectos da molecularidade ativa destas mulheres, do autor e de expectadores. Para nós, a obra instaura uma gama de referências práticas e teóricas que permitem uma educação que não está presa ao conhecimento útil, formal ou pré-formativo e que propõe condições de uma vida tanto individual quanto coletiva.

Ao final deste trabalho, reforça-se a ideia de que não há fim nos caminhos traçados nessa cartografia, mas a pista inicial nos trouxe, através dos movimentos descritos nesta conclusão, à composição do mapa dos fluxos contínuos percebidos no autor, personagens e obra na arte de Chico Ludemir. É nessa com-posição que o acontecimento educação surge, especialmente no agenciamento composto pelos contra-fluxos, re(x)istências e potências disruptivas encontradas que promoveram processos de diferenciação e transformação moleculares.

Percebe-se que o Acontecimento Educação também surge por caminhos incidentais, porque a ciência pensa a educação como conceito e se concentra em processos empíricos enquanto possibilidades já constituídas. Acrescentam-se então produções artísticas que resplandecem nas imagens-cristal dos curtas-metragens de vivências trans que entrelaçam em simbiose entre a filosofia e as artes como formas de pensamento.

Por tanto, discutir os processos educacionais incidentais a partir dos descostumes das fendas da cidade e, a partir de rizomas artísticos, deslocar proposições pedagógicas para um arejamento de possibilidades de se discutir o pensamento e o trânsito de corpos atemporais e sem lugar específico ou ordenável.

\footnotetext{
Resumo: A cartografia dos descostumes traz a possibilidade de gerarmos um mapa que espelha os fluxos contínuos contidos na Cartografia da obra de Chico Ludemir. Inspira-se numa função-artística e no nascer mulher dos devires transexuais que promovem a ideia de educações insurgentes a partir de agenciamentos artísticos, culturais e educacionais que comungam espaços e tempos. A problemática surge da possibilidade de que elementos artísticos em agenciamento constituam estratégias de re(x)istência no acontecimento educação, o que gerou, como pista inicial para percorrer os caminhos que chegaram a este trabalho, a necessidade de costurar um mapa dos fluxos contínuos na arte de Chico Ludemir que nos levasse ao acontecimento. Surgiram movimentos que nos permitem investigar a pista proposta e desenvolver nossa cartografia viva com ênfase na molecularidade de linhas de fugas educacionais a partir das subjetividades do autor, da obra e das personagens. Reforçamos, assim, que o acontecimento educação surge do agenciamento composto essencialmente dos contra-fluxos e fatores de re(x)istências das potências disruptivas encontradas que promoveram processos de diferenciação e transformação moleculares.
}

Palavras-chave: Molecularidade Ativa; Linhas de Fuga; Educação; Literatura; Arte. 


\begin{abstract}
The cartography of discontinuities brings about the possibility of generating a map mirroring continuous flows contained within the Cartography of Chico Ludemir's work. It is inspired by an artistic function and by the birth and becoming of a transgender woman and which promotes the idea of insurgent educational experiences based on artistic, cultural and educational agencies with shared spaces and times. The problem arises from the possibility that artistic elements in agency may constitute strategies of resistance (existence) in the educational event, which generated, as an initial clue to follow the paths that led to this work, the need to sew a map of continuous flows within Chico Ludemir's art, up to the event itself. Movements have emerged that allowed us to investigate the proposed track and to develop a living cartography emphasising the molecularity of educational escaping lines emanating from the subjectivities of the author, the work and the characters. We thus reinforce, that, the educational event arises from the agency, essentially composed by counter-flows and factors of resistance (existence) to the disruptive powers that promoted processes of molecular differentiation and transformation.
\end{abstract}

Keywords: Active Molecularity; Escaping Lines; Education; Literature; Art.

\title{
REFERÊNCIAS
}

ABREU, Caio Fernando. Onde andará Dulce Veiga? São Paulo: Companhia das Letras, 1990.

BARROS, Isabelle. Mulheres trans são tema de exposição na Fundação Joaquim Nabuco: fotógrafo Chico Ludermir acompanhou dez mulheres trans durante dois anos e fez fotos, vídeo e livro. Diário de Pernambuco, Recife, 23 jul. 2015. Disponível em: https://www.diariodepernambuco. com.br/noticia/viver/2015/07/mulheres-trans-sao-tema-de-exposicao-na-fundacao-joaquim-nabuco.html. Acesso em: 25 jun. 2017.

BAZANTE, Brenda. Brenda: A História Incompleta de Brenda e de Outras Mulheres. Canal Chico Ludemir, Recife, 23 jul. 2015. Disponível em: https://www.youtube.com/watch?v=OAjLRFw7i$-Y \& \mathrm{t}=9$ s. Acesso em: 25 jun. 2019.

BENEVIDES, Bruna G. Uma leitura sobre "A História Incompleta de Brenda e de Outras Mulheres...". Revista Cardamomo, Recife, 21 dez. 2016. Disponível em: http://www.revistacardamomo.com/uma-leitura-sobre-a-historia-de-brenda-e-outras-mulheres/. Acesso em: 22 jun. 2017.

BEZERRA, Eugênia. Chico Ludermir expõe obras sobre mulheres transexuais na Fundaj: "MuIheres: Nascer É Comprido" é formada por fotografias e vídeos. A mostra pode ser visitada no prédio da fundação no Derby. Jornal do Commércio, Recife, 23 jul. 2015. Disponível em: https://jc.ne10.uol.com.br/canal/cultura/artes-plasticas/noticia/2015/07/23/chico-ludermir-expoe-obras-sobre-mulheres-transexuais-na-fundaj-191502.php. Acesso em: 26 jun. 2017.

BHABHA, Homi. O local da cultura. Belo Horizonte: Editora UFMG, 2003.

BRASILEIRO, Paula. Exposição retrata transformações de transexuais: 'Mulheres: nascer é comprido', do fotógrafo Chico Ludermir, mostra a transição e o dia a dia de 10 mulheres trans do Recife. Leia já, Recife, 23 jul. 2015. Disponível em: https://www1.leiaja.com/cultura/2015/07/23/ exposicao-retrata-transformacoes-de-transexuais/. Acesso em: 25 jun. 2017.

CARVALHO, Alexandre Filordi de Carvalho. Função-educador e atualidade: ponderações foucaultianas para a educação. In: BRITO, Maria dos Remédios de; GALLO, Silvio (orgs.). Filosofias da Diferença e Educação. São Paulo: Editora Livraria da Física, 2016. p. 243-266.

CASTRO, Luiz Guilherme Rivera de. Outros espaços e tempos, heterotopias. In: CONGRESSO INTERNACIONAL ESPAÇOS PÚBLICOS, 1., 2015, Porto Alegre, RS. Anais [...]. Porto Alegre: EDIPUCRS, 2015. Disponível em: https://edisciplinas.usp.br/pluginfile.php/1807535/mod_resource/content/ 1/Castro.pdf. Acesso em: dez. 2017.

DELEUZE, Gilles. Cinema 2: a imagem-tempo, São Paulo, Brasiliense,1990. 
DELEUZE, Gilles. Sobre o teatro. Rio de Janeiro: Zahar, 2010.

DI LAURETIS, Teresa. A tecnologia de gênero. In: HOLANDA, Heloisa Buarque de (Org.). Tendências e impasses: o feminismo como crítica cultural. Rio de Janeiro: Rocco, 1994.

DINIS, Nilson Fernandes. Educação, cinema e alteridade. Educar em Revista, n. 26, p. 01-13, 2005.

FOUCAULT, Michel. Outros espaços. Conferência proferida por Michel Foucault no Cercle d'Études Architecturales, em 14 de Março de 1967. Disponível em: https://historiacultural.mpbnet.com.br/pos-modernismo/Foucault-De_Outros_Espacos.pdf. Acesso em: 29 dez. 2019.

FOUCAULT, Michel. História da sexualidade I: A vontade de saber. Rio de Janeiro: Edições Graal, 1988.

FOUCAULT, Michel. A arqueologia do saber. Rio de Janeiro: Forense Universitária, 1995.

FOUCAULT, Michel. Ditos e Escritos: v. IV: estratégia poder-saber. Rio de Janeiro: Forense universitária, 2001.

FOUCAULT, Michel. A hermenêutica do sujeito. São Pulo: Martins Fontes, 2004.

FOUCAULT, Michel. A verdade e as formas jurídicas. Rio de Janeiro: Nau editora, 2005.

FREIRE, Simone. Travestis e mulheres trans negras que estão transformando o país, e você precisa conhecer. Disponível em: https://www.almapreta.com/editorias/realidade/travestis-e-mulheres-trans-negras-que-estao-transformando-o-pais-e-voce-precisa-conhecer. Acesso em: 29 dez. 2019.

FUNDAÇÃO JOAQUIM NABUCO (FUNDAJ). "Arte, reforma e revolução" manterá viva a FUNDAJ derby. Blog da Fundação, Recife, 12 fev. 2015. Disponível em: https://www.fundaj.gov. br/index.php/inventarios-documentais-e-indices-bibliotecas/131-blog-da-fundacao/noticias/577-arte-reforma-e-revolucao-mantera-viva-a-fundaj-derby. Acesso em: 2 jun. 2017.

G1. Pesquisa de Chico Ludemir durou dois anos e está em cartaz na Fundaj. G1, Recife, 23 jul. 2015. Disponível em: http:/g1.globo.com/pernambuco/noticia/2015/07/exposicao-reune-transformacoes-e-historias-de-transexuais-no-recife.html. Acesso em: 24 jun. 2017.

JOGO DE CENA. In: Enciclopédia itaú cultural de arte e cultura brasileiras. São Paulo: Itaú Cultural, 2020. Disponível em: http://enciclopedia.itaucultural.org.br/obra67310/jogo-de-cena. Acesso em: 30 mai. 2020. Verbete da Enciclopédia.

KRUTZEN, Eugênia Correia. Discurso e autoria: a escrita terapêutica. In: ALBUQUERQUE JÚNIOR, Durval Muniz de; VEIGA-NETO, Alfredo; SOUZA FILHO, Alípio (orgs.). Cartografias de Foucault. Belo Horizonte: Autêntica, 2011.

LOURO, Guacira Lopes. Gênero, sexualidade e educação: das afinidades políticas às tensões teórico-metodológicas. Educação em Revista, Belo Horizonte, n. 46, p. 201-218, dez. 2007.

LUDERMIR, Chico. A História Incompleta de Brenda e de Outras Mulheres. Rio de Janeiro: Confraria do Vento, 2016.

LUDERMIR, Chico. Encontros que tornam bela a incompletude. CEPE - Companhia Editora de Pernambuco: Suplemento Pernambuco, Recife, 23 mar. 2017. Disponível em: http://www.suplementopernambuco.com.br/edições-anteriores/67-bastidores/1832-encontros-que-tornam-bela-a-incompletude.html. Acesso em: 23 jun. 2017.

MACIEL, Auterives. Clínica, indeterminação e biopoder. Direitos humanos? o que temos a ver com isso? Comissão de Direitos Humanos do CRP-RJ [org.] Rio de Janeiro: Consellho Regional de Psicologia- RJ, 2007. 
MACLENNAN, Gloria Crespo. Wolfgang Tillmans, a fotografia sem limites: A Tate Modern expõe a obra do fotógrafo, considerado um dos artistas mais inovadores do momento. El País, Madrid, 17 fev. 2017. Disponível em: https://brasil.elpais.com/brasil/2017/02/16/cultura/1487253964_955625. html. Acesso em: 20 jul. 2020.

PACCE, Lilian. Bettina Rheims, feminilidade à flor da pele. Lilian Pacce, São Paulo, 19 fev. 2017. Disponível em: https://www.lilianpacce.com.br/e-mais/bettina-rheims-feminilidade-a-flor-da-pele. Acesso em: 20 jul. 2020.

PESSOA, Breno. Autor pernambucano lança livro com narrativas sobre mulheres trans e travestis recifenses Obra terá lançamento neste sábado, na Festa Literária das Periferias, na Cidade de Deus, Rio de Janeiro. Diário de Pernambuco, Recife, 12 nov. 2016. Disponível em: https:// www.diariodepernambuco.com.br/noticia/viver/2016/11/escritor-e-fotografo-pernambucano-lanca-livro-com-narrativas-sobre-mul.html. Acesso em: 23 jun. 2017.

ROLNIK, Suelly. Geopolítica da cafetinagem. Ide, São Paulo, v. 29, p. 123-129, 2006. Direitos Humanos? o que temos a ver com isso? Comissão de Direitos Humanos do CRP-R] [org.] Rio de Janeiro: Conselho Regional de Psicologia- RJ, 2007.

ROLNIK, Suely. Flowerings of Reality/Florações da Realidade. In: DE ZEGHER, Catherine. (Org.). Vida Afora /Life Line. Anna Maria Maiolino. New York: The Drawing Center, 2006. p. 107-112.

ROLNIK, Suely. Molda-se uma alma contemporânea: o vazio-pleno de Lygia Clark. The Experimental Exercise of Freedom: Lygia Clark, Gego, Mathias Goeritz, Hélio Oiticica and Mira Schendel, 1999.

ROLNIK, Suely. Subjetividade em obra: Lygia Clark, artista contemporânea. Projeto História: Revista do Programa de Estudos Pós-Graduados de História, v. 25, 2002.

ROLNIK, Suely. Cartografia sentimental: transformações contemporâneas do desejo. Porto Alegre: Sulina; Editora da UFRGS, 2014.

ROLNIK, S. A hora da micropolítica. Goethe Institut, 2016. Disponível em: https://www.goethe. de/ins/br/pt/kul/fok/rul/20790860.html. Acesso em: 15 out. 2017.

ROLNIK, S. Toxicômanos de identidade: subjetividade em tempo de globalização. Cultura e subjetividade. Saberes Nômades, Campinas, p. 19-24, 1997.

ROMANELLI, Rayanne. Rayanne: A História Incompleta de Brenda e de Outras Mulheres. Disponível em: https://www.youtube.com/watch?v=FWO0sndRbqA\&t=42s. Acesso em: 25 jun. 2019.

SCHÉRER, René. Aprender com Deleuze. Educação \& Sociedade, v. 26, n. 93, p. 1183-1194, 2005.

SENA, Maria Clara Araújo. Maria Clara: A História Incompleta de Brenda e de Outras Mulheres. Disponível em: https://www.youtube.com/watch?v=pxwN_DjQTz4\&t=31s. Acesso em: 25 jun. 2019.

SOUSA, Ilza Matias de Sousa. Clarice Lispector, "perto do coração selvagem": uma cartografia das singularidades selvagens à luz de Michel Foucault. In: ALBUQUERQUE JÚNIOR, Durval Muniz de; VEIGA-NETO, Alfredo; SOUZA FILHO, Alípio (orgs.). Cartografias de Foucault. Belo Horizonte: Autêntica, 2011.

UNIVERSIDADE DE PERNAMBUCO. NISC/UPE: Núcleo Integrado de Saúde Coletiva da Universidade de Pernambuco. Disponível em: http://www.upe.br/nisc.html\#: :text=O\%20 N\%C3\%BAcleo\%20Integrado\%20de\%20Sa\%C3\%BAde, pesquisa \%2C\%20de\%20 extens\%C3\%A3o\%20e\%20de. Acesso em: 25 mai. 2018. 
VEIGA-NETO, Alfredo. Foucault \& a Educação. Belo Horizonte: Autêntica, 2003.

YAHN, Camila. Nan Goldin: mergulhe no trabalho da artista que passa pelo Brasil nesta semana. Fashion Forward UOL, São Paulo, 30 de out. de 2017. Disponível em: https://ffw.uol.com. br/noticias/fotografia/nan-goldin-mergulhe-no-trabalho-da-artista-que-passa-pelo-brasil-nesta-semana/l . Acesso em: 20 jul. 2020.

Recebido em Novembro de 2020

Aprovado em Março de 2021 